\title{
Uma Abordagem Socio-técnica para Apoiar Ecossistemas de Software
}

\author{
Thaiana Lima, Gabriel Barbosa, Rodrigo Pereira dos Santos, Cláudia Werner \\ COPPE/UFRJ - Universidade Federal do Rio de Janeiro \\ Caixa Postal 68511 - CEP 21941-972 - Rio de janeiro, RJ, Brasil \\ \{thaiana, gabrielsb, rps, werner\}@cos.ufrj.br
}

\begin{abstract}
Software Ecosystems (SECO) emerge from networks created by actors around a common technological platform, which is centered in a software product. Due to the different types of interactions within a SECO, these networks are no longer exclusively social; they include both actors and artifacts. In order to better visualize, organize and use networks in SECOs, this paper describes an approach to organize their elements through sociotechnical networks, called SocialSECO. A comparative analysis between SocialSECO and a real case of a SECO platform is also presented to initially verify the presence of social resources in SECOs.
\end{abstract}

Resumo. Ecossistemas de Software (ECOSs) surgem de interações entre atores em torno de uma plataforma tecnológica comum, centrada em um produto de software. Devido aos diferentes tipos de interação em um ECOS, as redes criadas não são exclusivamente sociais; elas incluem tanto atores como artefatos. A fim de melhor visualizar, organizar e utilizar redes em ECOSs, este artigo descreve uma abordagem para organizar os elementos de ECOSs por meio de redes socio-técnicas, chamada SocialSECO. Apresenta-se ainda uma análise comparativa entre a SocialSECO e um caso real de plataforma de ECOS para verificar inicialmente a presença dos recursos sociais em ECOS.

\section{Introdução}

Um Ecossistema de Software (ECOS) pode ser descrito como uma rede de atores interagindo entre si e soluções de software que apoiam essas interações, com o suporte de uma plataforma tecnológica (Bosch, 2009). À medida que uma organização deixa de construir um produto de software isolado e busca parcerias para abrir seus negócios, ela ultrapassa suas fronteiras e encontra um ecossistema formado por várias outras (Berk et al., 2010). Assim, há a necessidade de estudar os ECOSs como um conjunto formado por plataforma, rede de atores (stakeholders) e rede de artefatos (Santos \& Werner, 2012). A intensidade da interação entre atores e artefatos no ECOS leva à fusão das redes sociais ${ }^{1}$ e das redes técnicas ${ }^{2}$, resultando em uma rede socio-técnica, que abrange elementos e associações de ambas as redes. Por exemplo, relacionamentos entre equipes

\footnotetext{
${ }^{1}$ Rede social consiste em um grafo que representa o relacionamento social entre atores (nós).

${ }^{2}$ Rede técnica consiste em um grafo que representa interações ou dependências entre os artefatos (nós).
} 
em ECOSs podem ser identificados e representados pela troca de artefatos (e.g., código, documentos, componentes, entre outros) e pelos atores (Seichter et al., 2010).

Considerando que a informação persiste no ECOS por meio dos artefatos, novos tipos de relações são criados, de modo a associar atores e artefatos, agregando elementos tanto da rede social quanto da rede técnica. Portanto, as redes socio-técnicas abrangem atores, artefatos e relacionamentos, existentes e recém-criados, para atender as exigências emergentes da promoção dos artefatos ao nível de atores dos ECOSs. Isso leva à necessidade de representar os artefatos de forma mais clara na rede. Uma inspiração está nos sites de redes sociais, que proveem artifícios para explorar a visão dos seus membros e possibilitar a interação com outros elementos da rede, criando ecossistemas sociais. O perfil disponibilizado permite a exposição de características e acesso a artefatos compartilhados entre membros de uma comunidade ou equipe. Porém, o que é oferecido atualmente é relativo a redes sociais, e não a redes sociotécnicas. Especificamente no caso de um ECOS, a entidade central é o software e a equipe de desenvolvimento compartilha também artefatos relacionados.

Dessa forma, a rede técnica precisa ser ampliada para melhor representar os artefatos e suas características. Por exemplo, para manter um ECOS dinâmico, é necessário incentivar a participação dos atores e a renovação dos ativos de software. Tanto a comunicação e socialização dos atores, quanto a renovação de demandas ${ }^{3}$, precisam ser integradas no ECOS. Tendo como motivação a fusão das redes social e técnica, bem como a importância de entender as relações entre seus elementos (atores e artefatos), o objetivo deste trabalho é analisar os recursos sociais relevantes para ECOS que devem ser inseridos na rede técnica, oriunda de uma biblioteca de ativos de ECOS, além de seus elementos descritivos. Realiza-se uma descrição de diversos elementos considerados para um ECOS e propõe-se uma abordagem socio-técnica para apoiar ECOSs, denominada SocialSECO. Umas das contribuições da pesquisa é manter a informação contida na rede social, às vezes defasada pela rotatividade de atores, ao persistir o conhecimento do ECOS pelos artefatos. Além disso, a análise da saúde do ECOS por meio da identificação do estágio do ciclo de vida do ECOS é um benefício da aplicação da abordagem. Ou seja, ao visualizar suas propriedades, a rede sociotécnica e o estágio do ciclo de vida, a saúde do ECOS pode ser melhor compreendida.

Este artigo corresponde a uma extensão do artigo curto (Lima et al., 2013), publicado no II Brazilian Workshop on Social Network Analysis and Mining (BraSNAM'2013). Em Lima et al. (2013), foram identificados preliminarmente os elementos da estrutura do ECOS, i.e., atores, papéis, relacionamentos e módulos de uma proposta inicial para análise da rede sociotécnica de ECOSs. Nesta extensão incluiu-se: (i) expansão da fundamentação teórica, para discutir redes sociais e gestão de ativos em ECOS, bem como trabalhos relacionados e sua comparação com a abordagem proposta; (ii) evolução da pesquisa realizada, o que inclui o detalhamento dos ativos de ECOS e da arquitetura conceitual da abordagem SocialSECO a partir dos mecanismos sociais e de mineração de dados envolvidos; e (iii) apresentação de uma análise comparativa entre a abordagem SocialSECO e um caso real de plataforma de ECOS para verificar a presença dos recursos sociais em ECOS. Além desta seção introdutória, o artigo possui

\footnotetext{
${ }^{3}$ Uma demanda consiste em uma sugestão de novos requisitos de software sobre os artefatos.
} 
a seguinte estrutura: a Seção 2 discorre sobre a fundamentação teórica; a Seção 3 detalha a abordagem proposta; a Seção 4 discute uma análise comparativa entre a abordagem e um caso real de plataforma de ECOS; e a Seção 5 conclui o artigo.

\section{Fundamentação Teórica}

As redes sociais representam pessoas conectadas por uma ou várias relações, de forma a partilharem informações e valores. Como a definição de ECOS se refere a atores e suas interações, as redes sociais podem ser aplicadas na representação da rede que surge em um ECOS (Barbosa et al., 2013). Sites de redes sociais proporcionam o apoio tecnológico para as redes formadas, oferecendo diversos recursos, como a criação de comunidades para apoiar o trabalho colaborativo de equipes. Segundo Seichter et al. (2010), a comunicação e a interação entre esses atores são realizadas por meio dos artefatos que eles compartilham. Pelo fato dos atores terem uma rotatividade maior que os artefatos na rede, cria-se uma identidade para o artefato, transformando-o em um "cidadão de primeira classe" ao explorar a parte da rede que detém grande parte da informação, não contemplada antes nas redes sociais. Assim, os elementos da rede passam a ser pessoas, equipes ou empresas, e ativos de software (i.e., necessidades e artefatos), constituindo a rede socio-técnica (Hanssen \& Dyba, 2012).

Tendo em vista que um ECOS trata esses elementos, o uso desse tipo de rede visa mapear os elementos que possuem informação da plataforma e como se relacionam (Santos et al., 2012). Neste caso, a plataforma compreende a tecnologia de software central sobre a qual se dá a construção e manutenção do ECOS, e.g., Eclipse, Windows, SAP etc. (Manikas \& Hansen, 2013). Segundo algumas pesquisas mais específicas, normalmente, estas plataformas de alguma forma apresentam recursos sociais para integrar os atores do ECOS (Santos et al., 2014). Podem ainda ser apoiadas por bibliotecas de ativos de software para permitir a organização da rede técnica do ECOS (Albert et al., 2013). Visando identificar os possíveis papéis de um ator, pesquisou-se na literatura trabalhos sobre modelagem de ECOSs, conforme discutido preliminarmente em (Lima et al., 2013), o que resultou na categorização apresentada na Tabela 1.

\section{Tabela 1. Descrição dos papéis dos atores dos ECOSs. Fonte: (Lima et al., 2013)}

\begin{tabular}{|c|c|c|c|c|}
\hline$=$ & Keystone & \multicolumn{3}{|c|}{$\begin{array}{l}\text { Acrescenta valor para o ECOS e é o principal responsável pela manutenção da saúde, i.e., longevidade e } \\
\text { propensão ao crescimento (Hartigh et al., 2006). Pode representar a entidade de influência dominante. }\end{array}$} \\
\hline & Dominator & \multicolumn{3}{|c|}{ Extrai valor do ECOS, colocando em risco a sua saúde e sustentabilidade. } \\
\hline \multirow{9}{*}{ 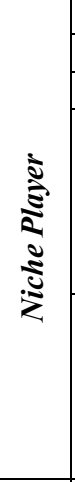 } & Customer & \multicolumn{3}{|c|}{ Representa o cliente, que gerou a necessidade dos produtos de software do ECOS. } \\
\hline & Competitor & \multicolumn{3}{|c|}{ Tenta extrair valor do ecossistema, porém não ameaça a saúde do ECOS. } \\
\hline & Supplier & \multicolumn{3}{|c|}{ Ator que fornece um ou mais produtos ou serviços necessários ao ECOS. } \\
\hline & \multirow{3}{*}{ Vendor } & \multirow{3}{*}{$\begin{array}{l}\text { Vende os } \\
\text { produtos de } \\
\text { software do } \\
\text { ECOS }\end{array}$} & Reseller & Revende um produto desenvolvido por outro ator sem alterá-lo. \\
\hline & & & \begin{tabular}{|c|} 
Indepedent Software \\
Vendor (ISV)
\end{tabular} & Produz e vende seu próprio produto. \\
\hline & & & $\begin{array}{l}\text { Value-added } \\
\text { Reseller (VAR) }\end{array}$ & $\begin{array}{l}\text { Revende um produto desenvolvido por outro ator, mas agrega } \\
\text { valor ao mesmo. }\end{array}$ \\
\hline & \multirow{3}{*}{ Developer } & \multirow{3}{*}{$\begin{array}{l}\text { Desenvolvedor } \\
\text { interno, ligado a } \\
\text { entidades } \\
\text { formadoras do } \\
\text { ECOS }\end{array}$} & Influencer & $\begin{array}{l}\text { Desenvolve para o ECOS e contribui para sua saúde ao se } \\
\text { comprometer com uma estratégia, complementando o Keystone }\end{array}$ \\
\hline & & & Hedger & $\begin{array}{l}\text { Desenvolve seus produtos ou serviços para apoiar múltiplas } \\
\text { plataformas. }\end{array}$ \\
\hline & & & Disciple & Compromete-se exclusivamente com a plataforma. \\
\hline \multirow{3}{*}{ 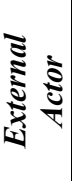 } & $\begin{array}{l}\text { 3rd-party } \\
\text { developers }\end{array}$ & \multicolumn{3}{|c|}{$\begin{array}{l}\text { Promove o ECOS e seus produtos, pode propor melhorias. Análogo ao Influencer, porém externo ao } \\
\text { ECOS, não tendo vínculo formal com o Keystone. }\end{array}$} \\
\hline & End-user & \multicolumn{3}{|c|}{ Usuário final do produto, difere do Customer, por não contratar serviço do Keystone. } \\
\hline & $\begin{array}{l}\text { External } \\
\text { Partner }\end{array}$ & \multicolumn{3}{|c|}{$\begin{array}{l}\text { Contribui para o bem estar do ECOS por meio de atitudes, tais como a promoção do ECOS e de seus } \\
\text { produtos. Também propõe melhorias. }\end{array}$} \\
\hline
\end{tabular}




\subsection{Gestão de Ativos em ECOS}

Ativos de software são artefatos produzidos ou adquiridos e armazenados por uma organização (Adams \& Govekar, 2012). No escopo deste trabalho, ativos de ECOS representam os produtos do ECOS, podendo ser ativos reutilizáveis (componentes e serviços) ou ativos de software (aplicações e necessidades ${ }^{4}$ ). Esta definição foi baseada em trabalhos prévios específicos ao tema de governança de ECOS (Baars \& Jansen, 2012; Rios, 2013; Albert, 2014). Por sua vez, a gestão de ativos de software envolve a melhora dos métodos para adquirir, implantar e utilizar ativos de software (Williams \& O'Connor, 2011). Para os ativos de ECOS, uma plataforma de ECOS pode ter apoio de uma biblioteca de ativos, responsável por gerenciar o seu ciclo de vida. Neste contexto, uma biblioteca de ativos corresponde a um sistema de informação com mecanismos de publicação, documentação, armazenamento, busca e recuperação de ativos de software (Santos \& Werner, 2013).

\subsection{Redes Sociais em ECOS}

O alcance das redes sociais incentiva organizações e comunidades a interagirem com as pessoas por meio de grupos, páginas pessoais e comerciais, entre outros, a fim de atingir seus objetivos (Boyd \& Ellison, 2007). As redes sociais podem expandir o ECOS, sendo utilizadas como um canal de comunicação e aproximação entre artefatos de software e atores do ECOS, comerciais ou não (Oliveira \& Santos, 2013). Conforme apresentado na Figura 1, Santos et al. (2014) discutem que o ciclo de vida social do ECOS, dividido em quatro fases, com base nos trabalhos de Russ (2007) e Jansen et al. (2009):

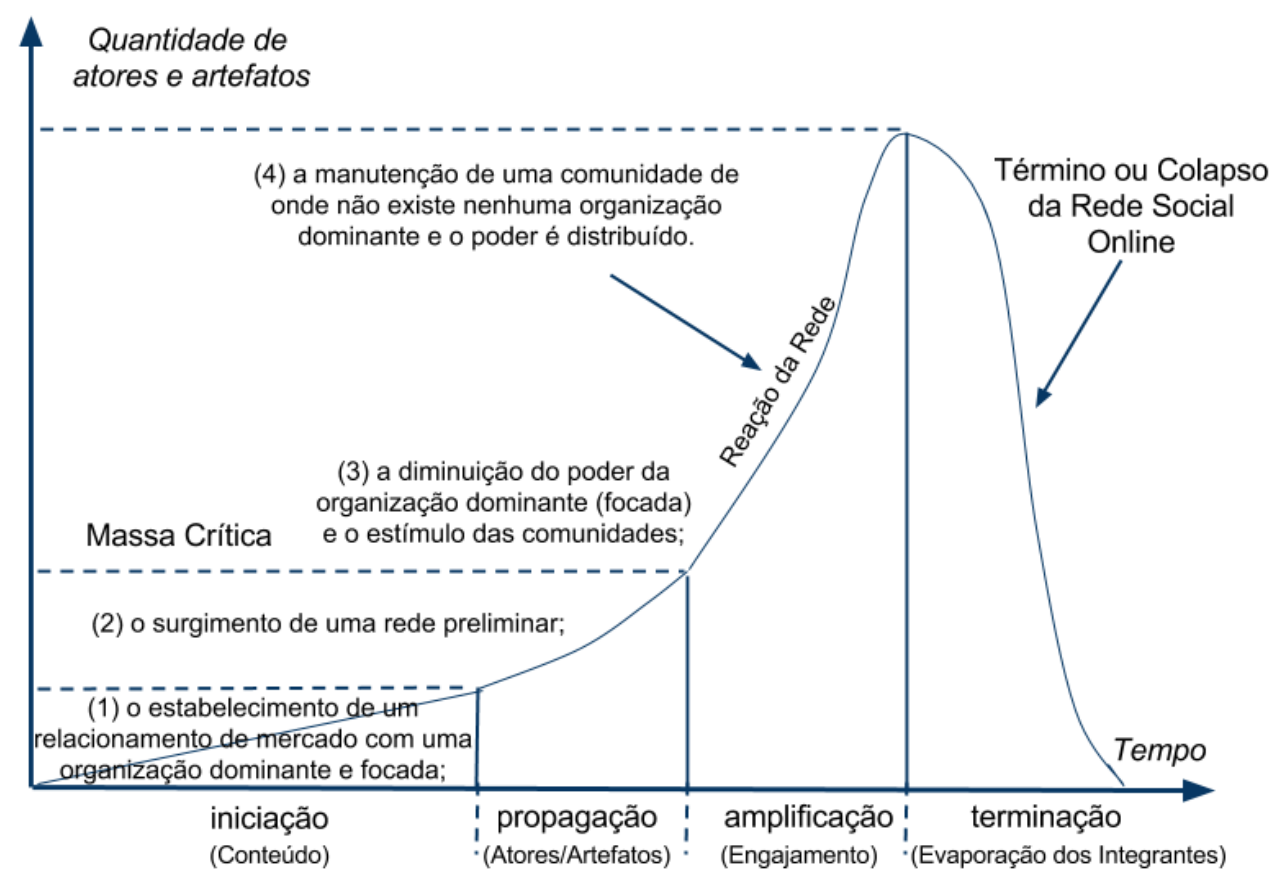

Figura 1. Relação entre o uso de rede social em ECOS e seu ciclo de vida. Fonte: (Santos et al., 2014)

\footnotetext{
${ }^{4}$ Necessidades dos stakeholders geram as demandas para o ECOS que, por sua vez, derivam requisitos de software e de sistemas para o desenvolvimento de novos artefatos para o ECOS.
} 
a) iniciação: criação de uma página em um site de rede social e/ou sistema de gerenciamento de comunidades e conteúdos;

b) propagação: adesão de novos atores e artefatos, i.e., surgimento de uma rede preliminar de atores com interesses em comum;

c) amplificação: estabelecimento de uma estrutura auto-organizável e manutenção de uma comunidade (rede de atores e artefatos), onde o poder é distribuído; e

d) terminação: normalmente, um serviço de rede social online termina devido à saturação ou à substituição por um novo serviço, ou ainda porque surgem novos nichos, mercados ou tendências que fazem com que ocorra uma "evaporação" dos integrantes da rede do ECOS.

Em cada fase do ciclo de vida social do ECOS, sites de redes sociais podem desempenhar um papel importante, principalmente devido à sua popularização e alcance. Além disso, o contato e a interação entre os atores também são facilitadas, incentivando a colaboração e formação de comunidades guiadas por interesses comuns.

\subsection{Trabalhos relacionados}

Em (Seichter et al., 2010), os participantes de um ECOS estão ligados a artefatos, de maneira que estes se comportem como "cidadãos de primeira classe"; porém, não se explora a questão dos papéis dos atores. Outro trabalho relacionado, que também não explora os papéis de um ator, é o descrito em (Mens \& Goeminne, 2011), cujo enfoque é a extração de informação de repositórios de projeto de software. Por outro lado, em (Capuruço \& Capretz, 2010), o foco não está nos artefatos e sim nos atores; o contexto das relações sociais é tratado, mas não na materialização da informação ou conhecimento em artefatos.

Por fim, Fricker (2009) apresenta algumas maneiras que o stakeholder influencia no processo de engenharia de requisitos em ECOS e aponta a negociação como solução ganha-ganha para tratar necessidades/demandas/requisitos em ECOS; entretanto, essas definições não tratam outros tipos de artefatos além de requisitos de software. A Tabela 2 apresenta as características em foco nesta pesquisa para comparar os trabalhos relacionados com a abordagem SocialSECO. Pode-se observar que nenhum deles tem foco em ambos os elementos formadores da rede (i.e., atores e artefatos). A partir das características apontadas, a abordagem proposta visa apoiar o tratamento de redes sociotécnicas, ao invés de lidar separadamente com redes sociais e redes técnicas.

Tabela 2. Comparação entre os trabalhos relacionados e a abordagem SocialSECO em relação às características em foco nesta pesquisa

\begin{tabular}{|l|c|c|c|c|c|}
\hline Característica & $\begin{array}{c}\text { Seichter } \\
\text { et al. (2010) }\end{array}$ & $\begin{array}{c}\text { Mens \& } \\
\text { Goeminne } \\
\text { (2011) }\end{array}$ & $\begin{array}{c}\text { Capuruço \& } \\
\text { Capretz (2010) }\end{array}$ & $\begin{array}{c}\text { Fricker } \\
\text { (2009) }\end{array}$ & SocialSECO \\
\hline Focam em artefatos & $\checkmark$ & $\checkmark$ & & $\checkmark$ & $\checkmark$ \\
\hline Focam em atores & & & $\checkmark$ & & $\checkmark$ \\
\hline Exploram relações sociais & $\checkmark$ & & $\checkmark$ & & $\checkmark$ \\
\hline $\begin{array}{l}\text { Lidam com o conhecimento } \\
\text { dos artefatos do ecossistema }\end{array}$ & & $\checkmark$ & & $\checkmark$ & $\checkmark$ \\
\hline $\begin{array}{l}\text { Manipulam redes socio- } \\
\text { técnicas em repositórios }\end{array}$ & & & & & $\checkmark$ \\
\hline $\begin{array}{l}\text { Contemplam os diferentes } \\
\text { papéis de um mesmo ator }\end{array}$ & & & & & $\checkmark$ \\
\hline
\end{tabular}




\section{Abordagem SocialSECO}

Com o intuito de explorar a dimensão social de ECOS, inicialmente, esta pesquisa se desenvolveu sobre a utilização de sites de rede social para apoiar a criação de uma rede sócio-técnica em ECOS por meio da sua integração com um ambiente de apoio à rede técnica (no caso, a biblioteca de ativos), conforme discutido em Lima et al. (2013). Entretanto, após a realização de pesquisas no âmbito de governança de ativos em ECOS (Albert et al., 2013) e de mecanismos sociais em ECOS (Santos et al., 2013), observouse que as plataformas de ECOS por si só agregam recursos sociais e que estes podem ser inseridos nas bibliotecas de ativos de ECOS. Nesse sentido, este artigo detalha a abordagem SocialSECO, cujo objetivo é organizar os elementos de ECOS em uma rede socio-técnica para apoiar a sua visualização e análise. Para concepção da SocialSECO, definem-se elementos formadores da rede, especificados nas subseções a seguir.

\subsection{Visão Geral}

A Figura 2 apresenta a visão geral da abordagem SocialSECO. Entre os seus elementos, incluem-se: mecanismos sociais, novos papéis, ativos de ECOS, métodos de análise (manipulação de grafos de rede), mineração de dados e uso de inteligência coletiva. Detalhes sobre estes elementos são descritos nas subseções a seguir.

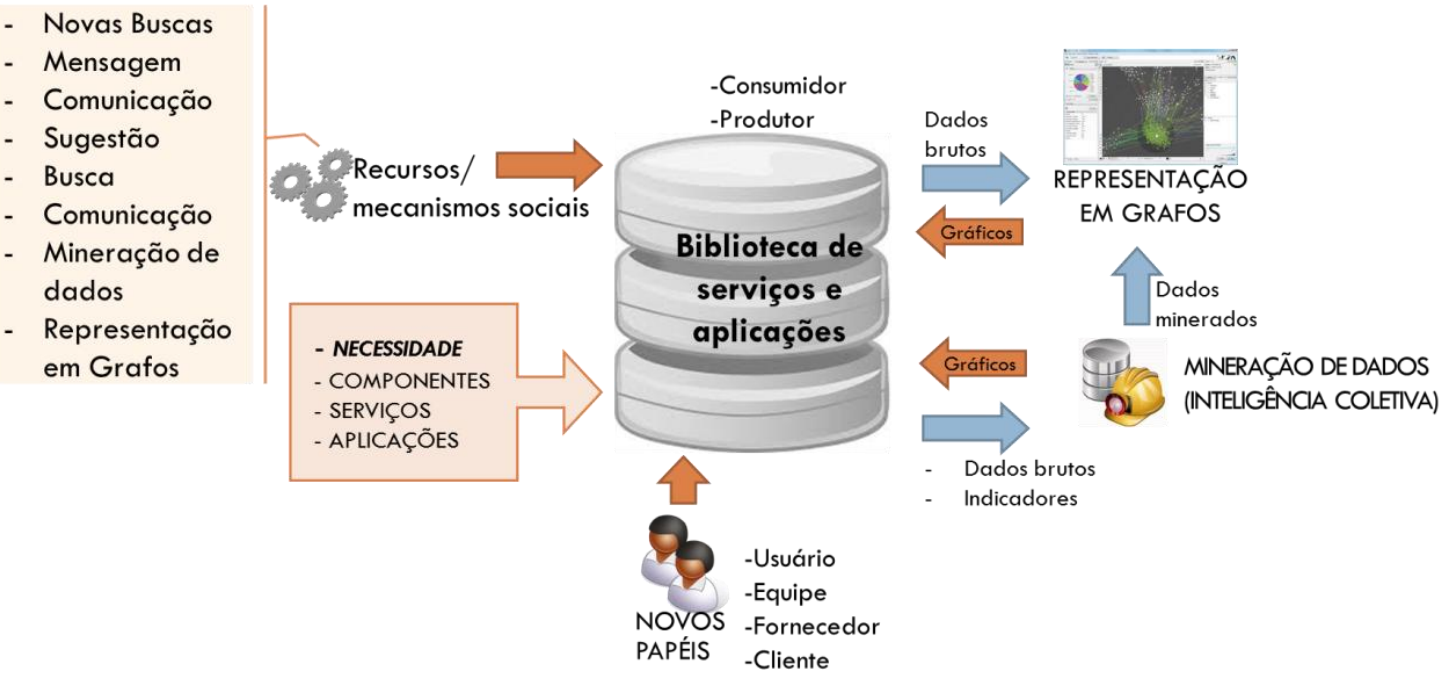

Figura 2. Disposição dos componentes

A Figura 2 mostra os elementos inseridos em uma biblioteca de ativos, que representa um repositório de artefatos que compõem a rede técnica (i.e., recursos sociais e ativos de ECOS, à esquerda). O objetivo é integrar funções e características de rede social para compor a estrutura de apoio ao ECOS a partir da rede socio-técnica formada. Alguns dados sobre a utilização da biblioteca são coletados e representados por meio de grafos, visando extrair informações ao executar algoritmos de mineração de dados e calcular métricas para entender o comportamento dos atores e artefatos (à direita). Entre essas informações, estão densidade da rede, grau médio e agrupamentos, que permitem identificar em que ponto do ciclo de vida esse ECOS se encontra. Este conhecimento é útil para os participantes-chave tenham uma visão do ECOS, que apoie decisões de investimento na plataforma, identifique necessidade de atualização de ativos, ou mesmo instigue a inserção de atores e interações entre eles. 


\subsection{Ativos de ECOS}

Para contemplar a parte da rede técnica, a abordagem SocialSECO define os ativos de software do ECOS (Santos, 2013), cuja categorização é apresentada pela Figura 3. Esta classificação divide os ativos em necessidades e artefatos. As necessidades representam os ativos que envolvem requisitos de software e as demandas que podem gerar tais requisitos, bem como outras necessidades no (ou para o) ECOS. Por sua vez, os artefatos, que podem ser comerciais ou não, correspondem a componente de software, serviço web e aplicações, bem como a sua documentação, modelos existentes etc. Estes ativos estão normalmente armazenados em bibliotecas de ativos de software, que consistem nos catálogos, como explicado na Subseção 2.1.

\section{Ativos de ECOS}

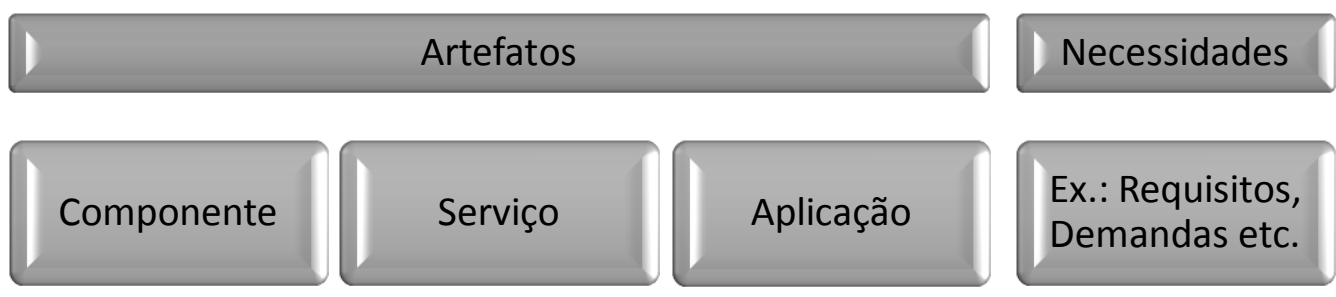

Figura 3. Definição de ativos de ECOS

\subsection{Papéis}

Como acontece nos ECOS, na abordagem SocialSECO, um ator pode exercer mais de um papel (Manikas \& Hansen, 2013). Se considerada a distinção de ativos discutida na Subseção 2.1, na gerência de ativos reutilizáveis, os papéis existentes normalmente são (Szyperski et al., 2002): (i) Produtor: que desenvolve o ativo reutilizável; (ii) Consumidor: que utiliza o ativo reutilizável para construção de soluções de software; e (iii) Gerente da Biblioteca: que realiza a manutenção da qualidade da base de ativos. Com foco na visão social, no conceito mais amplo de ativos de ECOS e nos resultados da organização feita na Tabela 1, percebe-se a necessidade de outros papéis em uma biblioteca de ativos de ECOS, que estão além da biblioteca de ativos reutilizáveis.

Nesse sentido, os papéis cliente, usuário, equipe e fornecedor são considerados pela abordagem SocialSECO. Os atores que exercem os papéis indicados podem ser pessoas, conjunto de pessoas, empresas ou comunidades. Cliente corresponde ao papel "Customer", responsável pela aquisição de software sob demanda especificada por este papel, e Usuário se refere ao papel "End User", descrito na Tabela 1. Vale ressaltar que, quando um ator participa do ECOS buscando informações dos artefatos e contribuindo com a especificação de necessidades, ele exerce o papel de usuário do software, sem obrigatoriedade de publicar ou adquirir um ativo de software. Um usuário pode ainda ter um conjunto de ferramentas padrão para ser utilizado em suas atividades cotidianas, equivalendo a uma configuração específica de ativos para o mesmo.

Por sua vez, Equipe representa um papel criado por um ator e administrado por ele ou por um grupo de atores. Cada ator em um papel Equipe pode adquirir ativos e/ou utilizar licenças de ativos existentes no ECOS. Uma Equipe pode ser formada por atores internos ou externos a uma organização, ou ainda de maneira mista, cabendo à empresa 
permitir a participação externa. Com relação à Tabela 1, Equipe se refere aos papéis "Niche Player" ou "External Actor", podendo envolver atores com diferentes papéis. Por fim, Fornecedor consiste no papel da organização que fornece uma tecnologia, e.g., Microsoft é o fornecedor do ativo Microsoft Word para uma organização. A diferença entre Produtor e Fornecedor está no fato de que este se relaciona com ativos de software (aplicações e necessidades), enquanto o primeiro se relaciona com ativos reutilizáveis (componentes e serviços), conforme explicado anteriormente. Na Tabela 1, Fornecedor equivale ao papel "Supplier", cujo ator, em algumas vezes, pode atuar como "Keystone" de outro ECOS formado em torno de sua plataforma (e.g., Microsoft é o keystone da plataforma Windows).

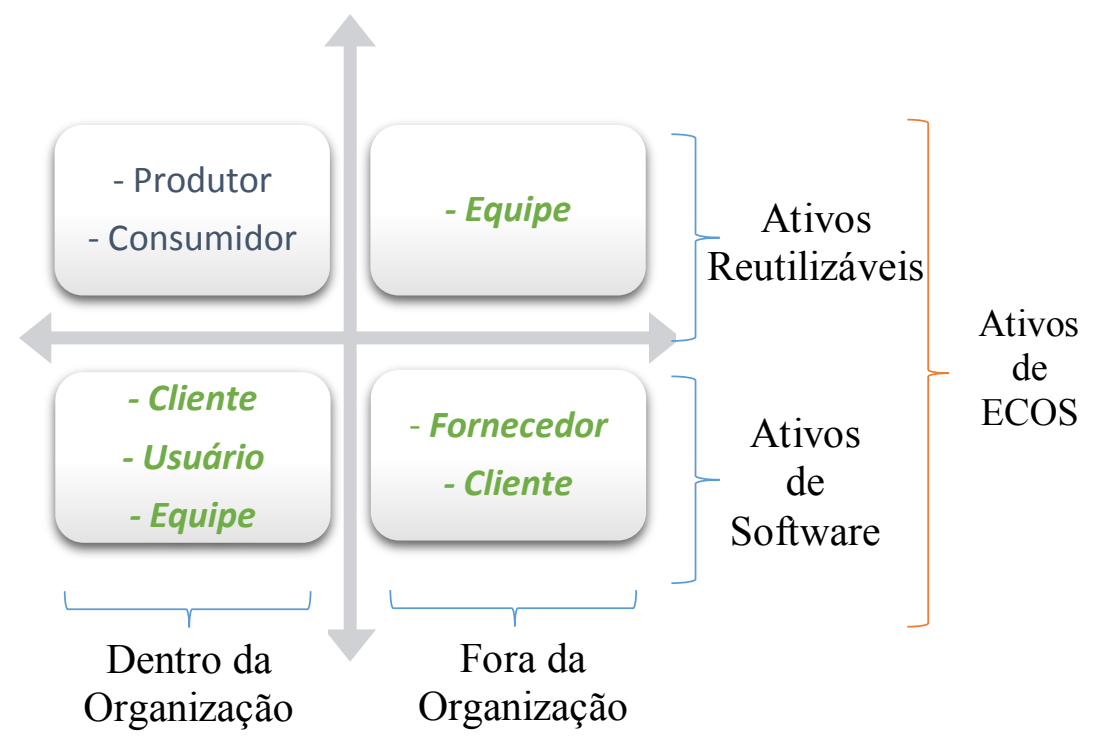

Figura 4. Classificação dos papéis de ECOS frente às visões interna e externa da organização e referentes ao tipo de ativo com o qual se relacionam

A Figura 4 mostra a disposição dos papéis (novos e existentes) nas visões intraorganizacional (dentro da organização) e interorganizacional (fora da organização), além de relacionar o tipo de ativo utilizado (reutilizável ou de software), conforme explicado na Subseção 2.1. Percebe-se que os novos papéis focam no suporte aos ativos de software, o que vai ao encontro da tendência de abertura das plataformas por parte das organizações centrais do ECOS ("Keystone”).

\subsection{Relacionamentos}

A criação dos relacionamentos se baseou na definição das novas interações a partir dos tipos possuido por, depende de, interessado em e membro de, estendendo o trabalho de (Seichter et al., 2010). Os novos relacionamentos foram definidos a partir das novas possibilidades de interação proporcionadas pelas redes sociais, conforme discutido em (Lima et al., 2013). Adicionalmente, em (Seichter et al., 2010), identificam-se oito recursos de sites de redes sociais importantes para mapear os relacionamentos de seus membros. Para o presente trabalho, a Tabela 3 apresenta a relação entre esses recursos e os elementos relacionados a bibliotecas de ativos de software, que visam apoiar as plataformas de ECOSs, no contexto da abordagem SocialSECO. 
A Tabela 4 apresenta os quatro tipos de interações definidos em Seichter (2010) seguidos dos quatro tipos acrescentados nesta pesquisa (Lima et al., 2013), também relacionadas com exemplos de como uma biblioteca de ativos lida com tais tipos de interações. As duas primeiras colunas são propostas de Seichter et al. (2010), a primeira mostra os tipos de interação provenientes dos relacionamentos entre artefatos e atores na fusão das redes sociais com as redes técnicas, e a segunda apresenta a descrição fornecida pelos autores. A terceira coluna é um mapeamento das características da SocialSECO que atendem aos respectivos tipos da primeira coluna.

Tabela 3. Relacionamentos entre elementos do ECOS tratados pela SocialSECO

\begin{tabular}{|c|c|c|}
\hline Relação & Definição & SocialSECO \\
\hline $\begin{array}{l}\text { Possuido } \\
\text { por }\end{array}$ & $\begin{array}{l}\text { Um artefato é possuído por um ator se este for o criador da } \\
\text { descrição do artefato. Este pode ainda ser possuído por vários } \\
\text { atores, e.g., caso em que um artefato pertence a uma equipe. }\end{array}$ & $\begin{array}{l}\text { Todo ativo tem um Produtor ou } \\
\text { Fornecedor e é possuído pelo ator } \\
\text { com este papel. }\end{array}$ \\
\hline $\begin{array}{l}\text { Depende } \\
\text { de }\end{array}$ & $\begin{array}{l}\text { Um artefato pode depender de outro, por ser um componente, } \\
\text { ou ter sido indicado pelo proprietário como tal. }\end{array}$ & $\begin{array}{l}\text { Dependência entre necessidades, } \\
\text { artefatos e/ou entre ambos. }\end{array}$ \\
\hline $\begin{array}{l}\text { Interessado } \\
\quad \text { em }\end{array}$ & $\begin{array}{l}\text { Quando a relação de interesse se estabelece, o interessado } \\
\text { indica a pretensão de receber atualizações sobre o ator/artefato. }\end{array}$ & $\begin{array}{l}\text { Recomendações baseadas nas } \\
\text { categorias de interesse do ator, nas } \\
\text { quais os artefatos são cadastrados. }\end{array}$ \\
\hline $\begin{array}{l}\text { Membro } \\
\text { de }\end{array}$ & Ser membro de uma comunidade. & O ator pode ser membro de um grupo. \\
\hline $\begin{array}{l}\text { Comunica } \\
\text { com }\end{array}$ & Troca de mensagens entre os participantes, incluindo artefatos. & Mensagem, fórum, atualizações. \\
\hline $\begin{array}{l}\text { Gerenciado } \\
\text { por }\end{array}$ & $\begin{array}{l}\text { Cada artefato é gerenciado por um único ator, responsável pelo } \\
\text { fornecimento e manutenção das informações do artefato. }\end{array}$ & $\begin{array}{l}\text { Gerenciado por quem tem os } \\
\text { privilégios de administrador do ativo. }\end{array}$ \\
\hline $\begin{array}{l}\text { Armazenado } \\
\text { em }\end{array}$ & $\begin{array}{l}\text { O site da rede social não armazena o artefato, este estará em } \\
\text { um repositório externo, identificado nesse relacionamento. }\end{array}$ & $\begin{array}{l}\text { O ativo fica armazenado na base de } \\
\text { dados da biblioteca de ativo de ECOS. }\end{array}$ \\
\hline $\begin{array}{l}\text { Originado } \\
\quad \text { por }\end{array}$ & $\begin{array}{l}\text { Relaciona a necessidade que gerou a criação de determinado } \\
\text { artefato, mantendo a rastreabilidade entre demandas e soluções } \\
\text { no ECOS. }\end{array}$ & $\begin{array}{l}\text { Cadastrar demandas nos artefatos, que } \\
\text { podem dar origem a requisitos de } \\
\text { software e de sistemas. }\end{array}$ \\
\hline
\end{tabular}

Tabela 4. Tipos de interações em ECOS, estendido de (Seichter et al., 2010), com alguns exemplos na SocialSECO

\begin{tabular}{|c|l|c|}
\hline Tipo de Interação & \multicolumn{1}{|c|}{ Descrição } & SocialSECO \\
\hline Ator $\rightarrow$ Ator & $\begin{array}{l}\text { Atores podem se comunicar por meio de mensagens, } \\
\text { grupos, entre outros. }\end{array}$ & $\begin{array}{c}\text { Mensagens, Grupos, } \\
\text { Negociação }\end{array}$ \\
\hline Ator $\rightarrow$ Artefato & $\begin{array}{l}\text { Incluir informações no artefato, classificação, } \\
\text { comentários. }\end{array}$ & $\begin{array}{c}\text { Informação da página do } \\
\text { ativo, Avaliação, Negociação }\end{array}$ \\
\hline Artefato $\rightarrow$ Ator & $\begin{array}{l}\text { Notificações geradas por alguma mudança no artefato, } \\
\text { como as informações visíveis de um repositório de } \\
\text { controle de versão. }\end{array}$ & Atualizações \\
\hline Artefato $\rightarrow$ Artefato & Relacionada à dependência entre artefatos. & $\begin{array}{l}\text { Dependência entre ativos e } \\
\text { informações de sua origem }\end{array}$ \\
\hline
\end{tabular}

\subsection{Mecanismos Sociais}

Para apoiar a concepção dos mecanismos sociais da abordagem SocialSECO, buscou-se na literatura uma relação de recursos sociais utilizados em ECOS, conforme discutido previamente em Lima et al. (2013), o que resultou na Tabela 5. Nesse sentido, a Figura 5 apresenta o relacionamento entre esses recursos sociais e os mecanismos propostos pela abordagem. Na Figura 5, os recursos sociais originados da Tabela 5 estão destacados em vermelho e compõem parte do mecanismo de socialização. Os mecanismos destacados em azul são propostos pela abordagem SocialSECO em combinação com Pontuação, Sugestão e Busca, que são encontrados em repositórios de componentes (rede técnica) (Santos et al., 2013). 
Tabela 5. Relação entre recursos de redes sociais identificados por (Seichter et al., 2010) e os elementos sociais da abordagem SocialSECO

\begin{tabular}{|c|l|c|}
\hline Recurso Social & \multicolumn{1}{|c|}{ Descrição } & SocialSECO \\
\hline Mural & $\begin{array}{l}\text { Modo de comunicar publicamente com outros usuários, } \\
\text { seja escrevendo no próprio mural ou no mural de outros } \\
\text { participantes. }\end{array}$ & Fórum \\
\hline Perfil & $\begin{array}{l}\text { Apresenta as informações sobre o usuário, por exemplo, } \\
\text { nome, endereço, entre outros dados, que normalmente } \\
\text { sofrem pouca modificação. }\end{array}$ & $\begin{array}{c}\text { Perfil de } \\
\text { usuário/ativo }\end{array}$ \\
\hline Atualização & $\begin{array}{l}\text { Exibe informações de atualizações de usuários e de } \\
\text { grupos. }\end{array}$ & "Top New Assets" \\
\hline Compartilhamento & $\begin{array}{l}\text { Publicação de vários tipos de arquivos, tais como fotos, } \\
\text { documentos e vídeos. }\end{array}$ & Arquivo de pacote \\
\hline Grupos & $\begin{array}{l}\text { Formação de grupos (abertos e/ou fechados), onde pessoas } \\
\text { com interesses em comum podem se organizar e receber } \\
\text { todo tipo de conteúdo postado no grupo. }\end{array}$ & Criação de grupos \\
\hline Busca & $\begin{array}{l}\text { Sistema de busca organizado, de maneira que os primeiros } \\
\text { resultados possuam relações diretas ou mais próximas que } \\
\text { os resultados posteriores listados. }\end{array}$ & $\begin{array}{c}\text { Pesquisa de } \\
\text { requisitos }\end{array}$ \\
\hline Sugestão & $\begin{array}{l}\text { Sistema que recomenda indivíduos ou grupos com } \\
\text { interesses similares. }\end{array}$ & $\begin{array}{c}\text { Sugestão } \\
\text { de ativos/requisitos }\end{array}$ \\
\hline Mensagem & Comunicação síncrona/assíncrona e privada. & Troca de mensagem \\
\hline
\end{tabular}

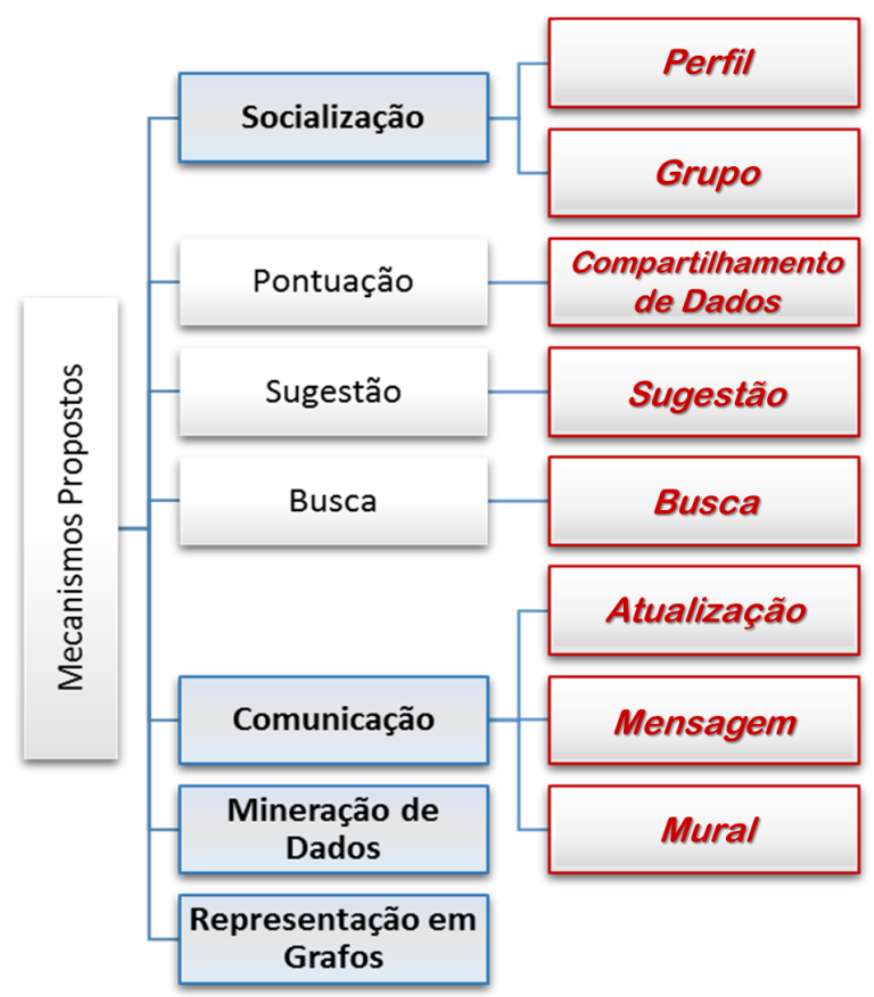

Figura 5. Relação entre mecanismos da SocialSECO e recursos sociais de ECOS

Os mecanismos sociais da abordagem SocialSECO são definidos a seguir:

1. Socialização: consiste em um conjunto de práticas e ferramentas disponibilizadas para os usuários interagirem de forma mais fácil e dinâmica em um ECOS, explorando dados de seu perfil e a formação de grupos. O objetivo é observar e analisar os atores e suas interações a partir dos artefatos do ECOS, visando criar novas relações e incentivar aquelas existentes. Os recursos de 
socialização devem utilizar artifícios de estímulo à colaboração, incentivo à comunicação e interação com outros usuários. Por exemplo, a formação de grupos incentiva a socialização, já que reúne atores com interesses em comum. Assim, perfis de usuário e as descrições de páginas que contenham suas informações precisam ser bem definidos. Esse mecanismo é concretizado por meio dos recursos sociais definidos na Figura 5;

2. Pontuação: visa estabelecer critérios para avaliar os atores (em seus respectivos papéis) e artefatos. O objetivo da pontuação é incentivar atividades tais como avaliações e aquisição de produtos (e.g., troca de ponto por descontos, ou recompensas por contribuições ao ECOS), tornando o ECOS mais dinâmico. As seguintes ações podem pontuar em um ECOS:

a. avaliar a negociação de ativos de ECOS;

b. realizar discussões sobre ativos de ECOS;

c. ser reconhecido pelas necessidades sugeridas;

d. ter mensagens bem cotadas nos fóruns;

e. sugerir demandas específicas para artefatos;

f. publicar ativos de ECOS.

3. Sugestão: envolve indicar ativos de ECOS que possam interessar a determinados papéis com base no perfil do ator, destacando os ativos do tipo "necessidade", a fim de fomentar a diversidade ${ }^{5}$ e a sustentabilidade ${ }^{6}$ (Dhungana et al., 2010). Além do histórico de aquisições e/ou uso e configurações do perfil, considera-se o histórico de visualização de ativos. Esse mecanismo pode sugerir ainda atores que tenham interesses em comum, assim como comunidades de interesse, criando uma rede socio-técnica para cada ator. Este mecanismo é concretizado por meio de algoritmos que calculem similaridade entre elementos do ECOS e que, portanto, possam ser recomendados ao ator;

4. Busca: visa refinar a informação específica que um ator, com determinado papel, tem interesse no ECOS. Esse mecanismo deve incluir a busca e recuperação de necessidades (não somente de artefatos). A concretização deste mecanismo se faz por meio da busca e recuperação de ativos de ECOS não contemplados na rede técnica em geral, por exemplo, requisitos de software e de sistemas;

5. Comunicação: tem por objetivo estimular a troca de mensagens, públicas ou privadas, entre atores do ECOS. Visa incentivar a comunicação em discussões e a colaboração entre os atores. Esse mecanismo envolve a construção de fóruns públicos e suporte ao envio de mensagens entre os atores do ECOS;

6. Mineração de Dados: utiliza algoritmos de inteligência coletiva para identificar ativos e discussões populares, possíveis associações entre ativos, atores com interesse em comum etc. Os dados coletados podem ser utilizados como entrada

\footnotetext{
${ }^{5}$ Sustentabilidade é capacidade de prover diversas oportunidades no ECOS

${ }^{6}$ Diversidade é capacidade do ECOS sobreviver às perdas e promover a sua reutilização e manutenção.
} 
para uma ferramenta de mineração, por exemplo. Algoritmos de agrupamento (clusterização), nuvem de tags, popularidade (mais acessados ou comentados) e similaridade (categorias comuns entre artefatos) para apoiar o mecanismo de sugestão devem ser incorporados na plataforma de ECOS;

7. Representação em Grafos: busca reproduzir a rede sócio-técnica ao aplicar a Teoria dos Grafos para modelagem de rede em ECOS, que utiliza nós para representar atores e ativos de ECOS, e arestas para os relacionamentos descritos anteriormente. $\mathrm{O}$ objetivo de inserir essa representação é permitir análises das relações dos ativos e atores, por exemplo, para obter medidas de importância ou influência do ativo da rede, i.e., o quanto um ator é influente em uma rede.

\subsection{Suporte ao Ciclo de Vida em ECOS}

Conforme discutido na Subseção 2.2, a Figura 1 apresenta o ciclo de vida social de um ECOS. Como os mecanismos da SocialSECO são baseados em recursos sociais, foi detectada uma relação entre estas propostas e as fases do ciclo de vida do ECOS. Nesse sentido, a Figura 6 introduz que mecanismos sociais mais auxiliam cada fase do ECOS. $\mathrm{Na}$ iniciação, por ser um momento de aumentar as conexões de um ator e permitir que ele encontre atores e artefatos no ECOS, os mecanismos de sugestão e de busca apoiam a formação da rede, culminando sua ação na fase de propagação. Nesta fase, os mecanismos de sugestão, busca, comunicação e socialização passam a ser responsáveis pelo crescimento da rede e, consequentemente, do ECOS. Na fase de amplificação, os mecanismos de socialização, comunicação e pontuação influenciam na formação de grupos, na troca de informações entre atores e na popularidade de artefatos pela própria comunidade (e.g., por meio do sistema de pontuação, que pode inserir ativos nas atualizações da rede), diminuindo o poder da organização dominante.

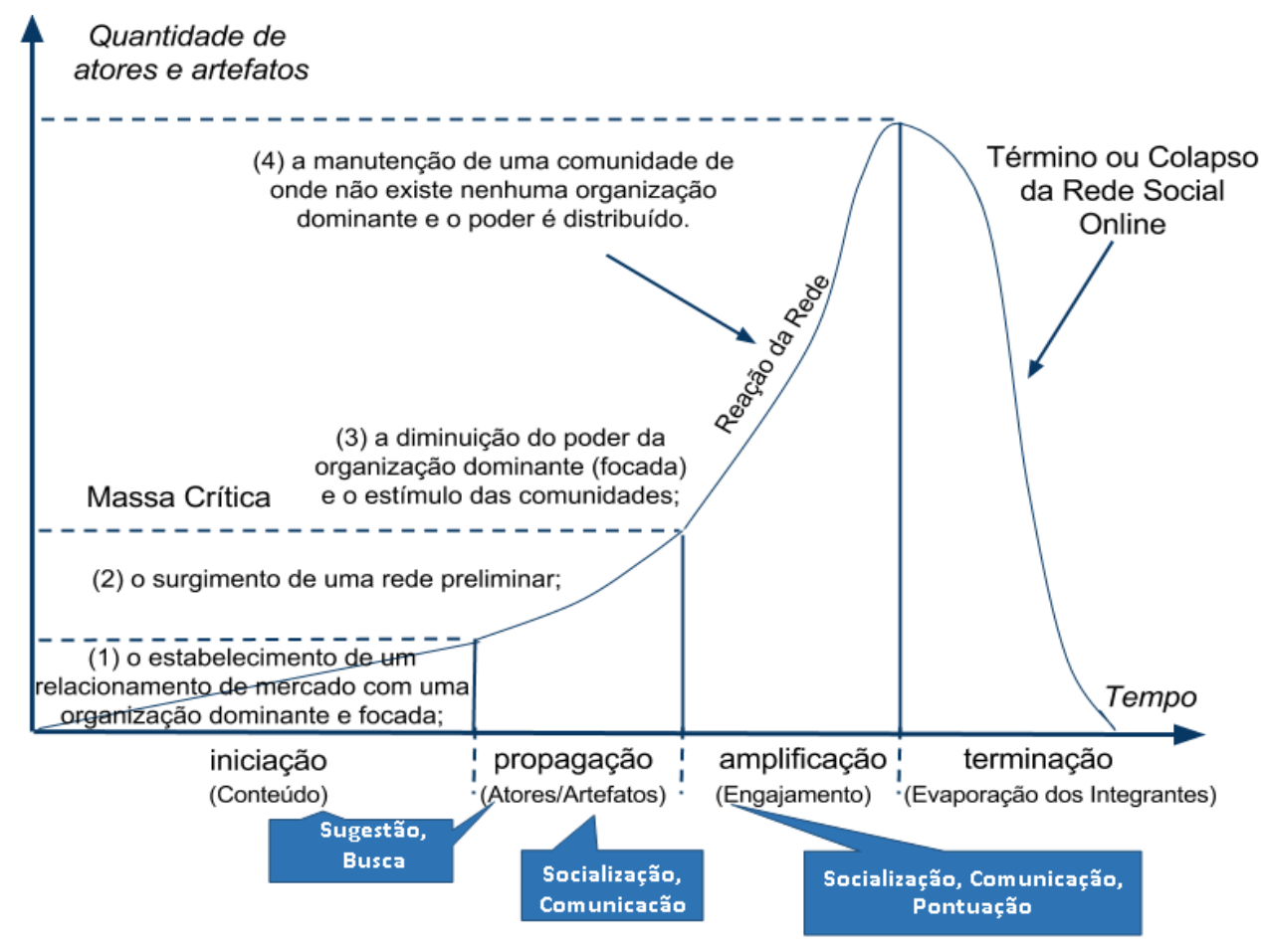

Figura 6. Apoio dos mecanismos sociais ao ciclo de vida do ECOS 


\section{Análise da Abordagem SocialSECO frente a um Caso Real de ECOS}

Com o objetivo de realizar uma análise comparativa entre a abordagem SocialSECO e um caso real de plataforma de ECOS, foi escolhido o caso do Portal do Software Público Brasileiro (SPB) (SPB, 2014). Essa análise visa verificar a presença dos recursos sociais em ECOS, ao comparar as propostas por meio de elementos comparativos (i.e., características, mecanismos, funcionalidades, conceitos etc.). Com isso, pretende-se verificar como a SocialSECO está aderente a um caso de ECOS.

O Portal SPB é um exemplo de ECOS brasileiro, composto por uma plataforma na qual qualquer cidadão pode se cadastrar para ter acesso às comunidades dos projetos de software brasileiros (Manikas \& Hansen, 2013). O Portal SPB se caracteriza por ser um ambiente de compartilhamento de software, com mais de 60 comunidades e mais de 200 mil usuários, que possui tanto uma visão social (propiciando a interação entre membros do portal) quanto técnica (catálogo de software). Na versão atual, o Portal SPB não acomoda ainda uma integração com ambientes colaborativos externos, principalmente de redes sociais. Existem 64 comunidades gerais, com usuários e desenvolvedores, e seis comunidades do governo.

Para a realização da análise comparativa, foram seguidas as seguintes etapas: (1) análise geral do Portal SBP, feita por dois pesquisadores; (2) revisão por pares dos elementos sociais gerais presentes no Portal SPB e na abordagem SocialSECO, pelos mesmos pesquisadores; (3) revisão por pares dos resultados obtidos em (2), por outros dois pesquisadores. A Figura 7 apresenta os passos seguidos.
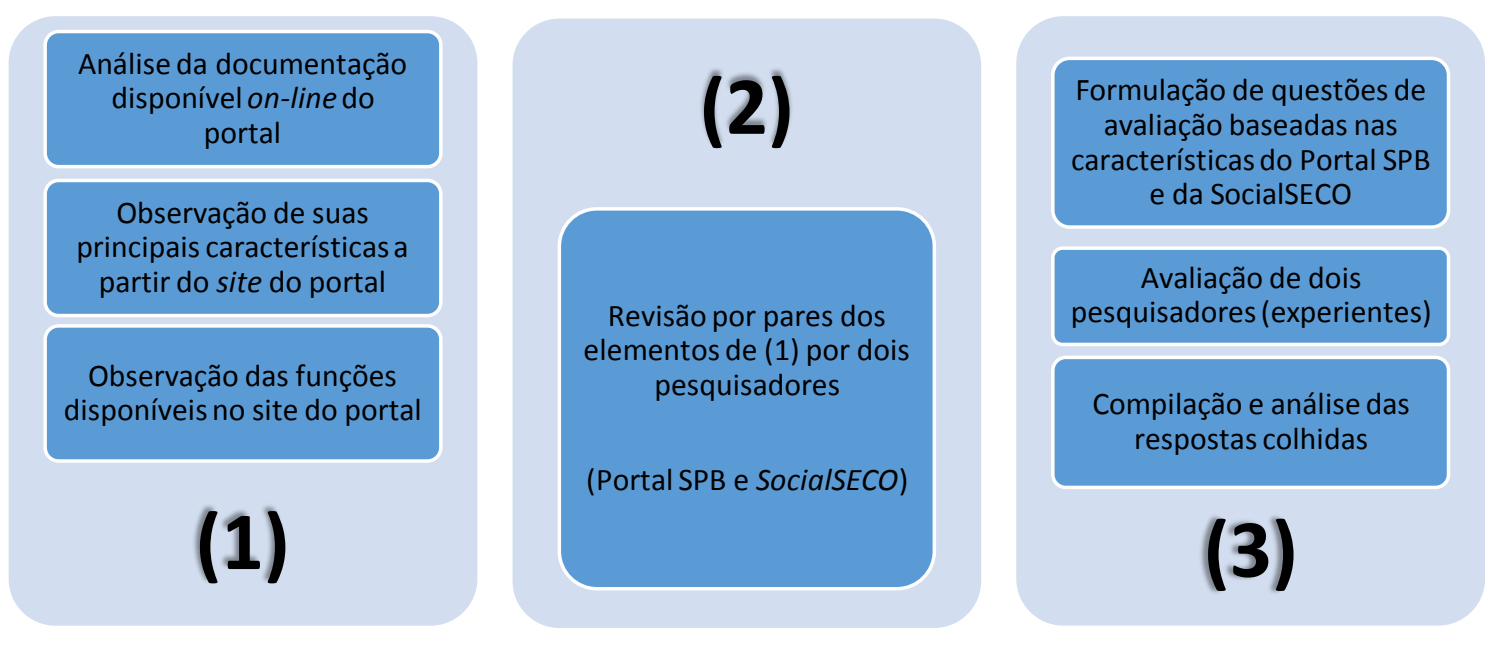

\section{Figura 7. Passos para a análise comparativa entre Portal SPB e SocialSECO}

A Tabela 6 apresenta os elementos sociais gerais encontrados no Portal SPB e aqueles envolvidos na abordagem SocialSECO. A numeração de cada elemento indica a fonte de referência, sendo: (1) proposta neste trabalho, com base em Lima et al. (2013); (2) Portal SPB; e (3) proposta em (Seichter et al., 2010). É feita uma comparação entre os recursos apontados nas plataformas em questão, resultando nas três situações representadas pelos seguintes símbolos $\checkmark$ : Atende; $\mathbf{x}$ : Não atende; e !: Atende parcialmente. Após a navegação realizada em pares por dois pesquisadores envolvidos neste trabalho, foram elencados 23 elementos sociais extraídos do Portal SPB. 
Tabela 6. Análise comparativa dos elementos sociais

\begin{tabular}{|c|c|c|}
\hline Elementos Sociais Gerais & 产 & 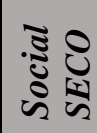 \\
\hline Fórum $^{2}$ & $\checkmark$ & $\checkmark$ \\
\hline Mensagem $^{2}$ & $\checkmark$ & $\checkmark$ \\
\hline Chat $^{2}$ & $\checkmark$ & $x$ \\
\hline Gestão de comunidades $^{2}$ & $\checkmark$ & $x$ \\
\hline Informações de outros membros ${ }^{2}$ & $\checkmark$ & $!$ \\
\hline Informações acerca de necessidades e demandas ${ }^{2}$ & $\checkmark$ & $\checkmark$ \\
\hline Armazenamento de arquivos $^{2}$ & $\checkmark$ & $\checkmark$ \\
\hline Wiki $^{2}$ & $\checkmark$ & $x$ \\
\hline Perguntas frequentes $(\mathrm{FAQ})^{2}$ & $\checkmark$ & $x$ \\
\hline Download de software ${ }^{2}$ & $\checkmark$ & $\checkmark$ \\
\hline Download de documentos (e.g., manual, apresentação, script etc.) $)^{2}$ & $\checkmark$ & $\checkmark$ \\
\hline Lista de prestadores de serviço ${ }^{2}$ & $\checkmark$ & $x$ \\
\hline Calendário $^{2}$ & $\checkmark$ & $x$ \\
\hline Weblogger $^{2}$ & $\checkmark$ & $x$ \\
\hline Questionários $^{2}$ & $\checkmark$ & $x$ \\
\hline Filtros de busca ${ }^{2}$ & $\checkmark$ & $\checkmark$ \\
\hline Avaliação ${ }^{2}$ & $\checkmark$ & $!$ \\
\hline Subgrupo em comunidades de software ${ }^{2}$ & $\checkmark$ & $x$ \\
\hline Meu espaço (área restrita do usuário) ${ }^{2}$ & $\checkmark$ & $!$ \\
\hline Busca por palavras-chave ${ }^{2}$ & $\checkmark$ & $\checkmark$ \\
\hline Mapa do site (Navegação) ${ }^{2}$ & $\checkmark$ & $x$ \\
\hline Relação externa (e.g., Facebook, Twitter, Feed RSS) ${ }^{2}$ & $\checkmark$ & $!$ \\
\hline Catálogo de software (exposição dos softwares que fazem parte do portal) ${ }^{2}$ & $\checkmark$ & $\checkmark$ \\
\hline Sistemas de recomendação para rede de pessoas e de comunidades ${ }^{3}$ & $x$ & $\checkmark$ \\
\hline Gestão de equipe de desenvolvimento e publicação conjunta de soluções de software ${ }^{1}$ & $x$ & $\checkmark$ \\
\hline $\begin{array}{l}\text { Pontuação para avaliação de demandas (usuários que avaliem demandas propostas pela } \\
\text { comunidade de desenvolvimento recebem bonificação) }\end{array}$ & $x$ & $\checkmark$ \\
\hline Sugestão de demandas ${ }^{1}$ & $x$ & $\checkmark$ \\
\hline Sugestão de comunidades com interesses similares ${ }^{3}$ & $x$ & $\checkmark$ \\
\hline Avaliação de discussões em fóruns (identificando tópicos mais relevantes) ${ }^{1}$ & $x$ & $\checkmark$ \\
\hline $\begin{array}{l}\text { Visualização da rede sócio-técnica do usuário (software produzido/consumido, } \\
\text { fornecedores, clientes, usuários) }\end{array}$ & $x$ & $\checkmark$ \\
\hline Página pessoal de usuário com mural para discussão com colegas e parceiros (wall) & $x$ & $\checkmark$ \\
\hline Negociação de demandas/necessidades/requisitos ${ }^{1}$ & $x$ & $\checkmark$ \\
\hline $\begin{array}{l}\text { Negociação de compra ou aquisição (incluindo licenças de uso) de ativos de software } \\
\text { (e.g., componentes de software, webservices, aplicações) }{ }^{1}\end{array}$ & $x$ & $\checkmark$ \\
\hline Avaliação de produtos de software ${ }^{1}$ & $!$ & $\checkmark$ \\
\hline $\begin{array}{l}\text { Busca avançada (e.g., filtrar por demanda/necessidade/requisito, tipo de arquivo como } \\
\text { aplicação, componente, manual etc.) })^{1}\end{array}$ & ! & $\checkmark$ \\
\hline Informações de licenças dos softwares ${ }^{1}$ & $x$ & $\checkmark$ \\
\hline Destaque de ativos populares $^{1}$ & $x$ & $\checkmark$ \\
\hline $\begin{array}{l}\text { Ponderação na avaliação de usuários (e.g., usuários mais experientes têm maior } \\
\text { credibilidade) }\end{array}$ & $x$ & $\checkmark$ \\
\hline
\end{tabular}

A discussão realizada com outros dois pesquisadores experientes mostrou que a abordagem SocialSECO atende a nove elementos sociais, não atende a dez deles, e atende parcialmente aos seguintes elementos: 
- Informações de outros membros: o Portal SPB possui informações adicionais sobre atuação dos atores em outros projetos de software, e a abordagem SocialSECO não contempla esse aspecto em sua concepção;

- Avaliação: a avaliação contemplada pelo mecanismo de pontuação da abordagem SocialSECO é relativa a ativos de ECOS utilizados e aos pares envolvidos na negociação de ativos reutilizáveis, enquanto o Portal SPB confere um campo mais aberto para avaliações nas comunidades;

- Meu espaço: o menu "meu espaço" do Portal SBP funciona como um painel de controle, centralizando as informações do usuário, ao passo que a abordagem SocialSECO não prevê uma área centralizada para isso em sua visão geral;

- Relação externa: o Portal SPB possui feed RSS, ao passo que a abordagem SocialSECO prevê interface com sites de redes sociais no mecanismo de socialização (e.g., botão "Curtir" do site de rede social Facebook).

Considerando 15 elementos sociais da abordagem SocialSECO, o Portal SPB não atende a 13 deles e atende parcialmente aos seguintes elementos:

- Avaliação de produtos de software: o Portal SPB não possui avaliação dos membros em suas atividades distintas, de demandas ou de negociação, as quais estão contempladas pela abordagem SocialSECO no mecanismo de pontuação;

- Busca avançada: a busca avançada do Portal SPB é limitada a um filtro de intervalo de data, ao passo que a abordagem SocialSECO prevê um mecanismo específico para contemplar os diferentes tipos de busca (e.g., para diferentes tipos de artefatos do ECOS).

Por fim, destaca-se que o Portal SPB oferece funções que não são previstas na abordagem SocialSECO, tais como Wiki, processo de avaliação para aprovar ou não o cadastro de novo software, entre outros. Além disso, a integração de um ambiente de gerência de projetos não é contemplado pela SocialSECO, uma vez que esta abordagem visa apoiar a plataforma de um ECOS ao explorar a socialização em um de seus elemento constituintes, i.e., a biblioteca de ativos de ECOS. Dessa forma, a SocialSECO abstrai detalhes do processo do desenvolvimento dos ativos de software, concentrandose no seu gerenciamento junto às necessidades e em seu suporte à plataforma do ECOS.

A metodologia aplicada possui algumas limitações, por exemplo, possibilidade de falha de observação: o Portal SPB pode possuir características marcadas como ausente por não terem sido observadas ou por necessitar de algum nível de privilégio ou autorização (não está especificada na documentação). Também pode ser considerada como limitação a pouca documentação disponível sobre as características do Portal SPB. Uma possível solução para estes problemas é contatar os gerentes do Portal SPB para ter acesso a dados que permitam refinar a análise. Além disso, o fato de serem comparados somente recursos implementados no Portal SPB e os mecanismos propostos pela SocialSECO colocaram em perspectiva a inserção ou remoção de tais recursos na abordagem, o que contribui para a atualização da abordagem.

\section{Conclusão}

Com a importância das redes que surgem das interações entre atores e artefatos na indústria de software, ECOSs vêm emergindo como um tópico de pesquisa e prática que visa investigar recursos para apoiar o desenvolvimento colaborativo e descentralizado em torno de plataformas de software. Como consequência, alguns obstáculos aparecem, 
como a gestão de papéis de atores, a compreensão de elementos de ECOS, a criação de comunidades com alto grau de relacionamento, e o enriquecimento dos artefatos e da plataforma com informação sobre o software (Manikas \& Hansen, 2013).

Dessa forma, analisar ECOSs e seus elementos, levando em consideração a visão social, se faz necessário para incentivar as relações entre os membros da rede. Paralelamente, a gestão dos ativos de ECOS realizada por bibliotecas de ativos de software muitas vezes carece de recursos sociais para dar suporte à interação entre os usuários e, assim, incentivar a colaboração. Este trabalho discutiu os recursos sociais relevantes para ECOS que devem ser inseridos na rede técnica, oriunda de uma biblioteca de ativos de ECOS, além de seus elementos descritivos. Elementos considerados importantes para um ECOS foram identificados, a fim de propor uma abordagem socio-técnica para apoiar ECOSs, denominada SocialSECO. A abordagem SocialSECO foi verificada preliminarmente por meio de uma análise comparativa com um caso real de plataforma de ECOS, o Portal SPB.

Destaca-se que esta pesquisa se motiva justamente pela carência de trabalhos que lidem com a dimensão social de ECOS em um nível de abstração mais elevado (Hanssen \& Dyba, 2012), i.e., no âmbito da governança de ativos de ECOS e de modelagem e análise da rede socio-técnica do ECOS. Os trabalhos normalmente focam na modelagem e análise de redes técnicas extraídas a partir de repositórios de gerência de configuração (Iyer, 2012). Além disso, como contribuição, espera-se melhorar a compreensão dos elementos envolvidos nas redes que se formam no cenário dos ECOSs e tratar aspectos sociais da Engenharia de Software, apontados como desafios para os próximos anos (Boehm, 2006; Dhungana et al., 2010; Mens \& Goeminne, 2011).

Como trabalho futuro, foi planejado e está em execução um estudo experimental (survey) com o objetivo de avaliar todos os elementos sociais, elencados na Seção 4, segundo a opinião de especialistas em ECOS e em sistemas colaborativos. Pretende-se ainda realizar um mapeamento sistemático da literatura de sistemas colaborativos visando capturar elementos sociais discutidos por esta comunidade, que se aplicam no cenário de ECOS. Espera-se com isso que a abordagem possa ser refinada. Além disso, uma infraestrutura de apoio à abordagem está sendo preparada a partir de uma extensão da Biblioteca de Componentes e Serviços Brechó (Werner et al., 2009), incluindo adaptações para a implementação de mecanismos sociais para ECOS (Santos et al., 2013), bem como a gerência de todos os tipos de ativos de ECOS, incluindo necessidades (Santos \& Werner, 2013).

\section{Agradecimentos}

Os autores gostariam de agradecer ao CNPq, CAPES (Proc. $n^{\circ}$. BEX 0204/14-5) e a FAPERJ pelo apoio financeiro para realização deste trabalho.

\section{Referências}

Adams, P., Govekar, M. (2012) “Hype Cycle for IT Operations Management”. Gartner Technical Professional Advice.

Albert, B. (2014) "SECOGov: Um Modelo de Governança de Ecossistemas de Software para Apoiar Atividades de Arquitetura de TI". Dissertação. COPPE/UFRJ, Rio de Janeiro, Brasil. 
Albert, B., Santos, R., Werner, C. (2013) "Software Ecosystems Governance to Enable IT Architecture Based on Software Asset Management". In: Proceedings of the 7th IEEE International Conference on Digital Ecosystem Technologies, Menlo Park, USA, pp. 55-60.

Baars, A., Jansen, S. (2012) “A Framework for Software Ecosystem Governance”. In: Proceedings of the Third International Conference on Software Business, Boston, USA, pp. 168-180.

Barbosa, O., Santos, R., Alves, C., Werner, C., Jansen, S. (2013) "A Systematic Mapping Study on Software Ecosystems through a Three-dimensional Perspective". In: Jansen, S., Cusumano, M., Brinkkemper, S. (eds.) "Software Ecosystems: Analyzing and Managing Business Networks in the Software Industry", pp. 59-81. Edward Elgar Publishing.

Berk, I., Jansen, S., Luinenburg L. (2010) "Software Ecosystems: A Software Ecosystem Strategy Assessment Model". In: Proceedings of the 4th European Conference on Software Architecture, 2nd International Workshop on Software Ecosystems, Copenhagen, Denmark, pp. 135-142.

Boehm, B. (2006) “A View of 20th and 21st Century Software Engineering”. In: Proceedings of the 28th International Conference on Software Engineering, Shanghai, China, pp. 12-29.

Bosch, J. (2009) "From Software Product Lines to Software Ecosystem", In: Proceedings of the 13th International Software Product Line Conference, San Francisco, USA, pp. 1-10.

Boyd, D.M., Ellison, N.B. (2007) "Social Network Sites: Definition, History, and Scholarship". Journal of Computer-Mediated Communication v. 13, n. 1, Article 11.

Capuruço, R.A.C., Capretz, L.F. (2010) "Integrating Recommender Information in Social Ecosystems Decisions". In: Proceedings of the 4th European Conference on Software Architecture, 2nd International Workshop on Software Ecosystems, Copenhagen, Denmark, pp. 143-150.

Dhungana, D., Groher, I., Schludermann, E., Biffl, S. (2010) "Software Ecosystems vs. Natural Ecosystems: Learning from the Ingenious Mind of Nature". In: Proceedings of the 4th European Conference on Software Architecture, 2nd International Workshop on Software Ecosystems, Copenhagen, Denmark, pp. 96-102.

Fricker, S. (2009) "Specifications and Analysis of Requirements Negotiation Strategy in Software Ecosystems". In: Proceedings of the First International Workshop on Software Ecosystems, 11th International Conference on Software Reuse, Falls Church, USA, pp. 19-33.

Hanssen, G., Dyba, T. (2012) "Theoretical Foundations of Software Ecosystems". In: Proceedings of the 4th International Workshop on Software Ecosystems, 3rd International Conference on Software Business, Boston, USA, pp. 6-17.

Hartigh, E., Tol, M., Visscher, W. (2006) "The Health Measurement of a Business Ecosystem". In: ECCON 2006 Annual Meeting, Bergen aan Zee, Netherlands pp. 139.

LIMA, T.; BARBOSA, G.; SANTOS, R. P.; WERNER, C.

Uma Abordagem Socio-técnica para Apoiar Ecossistemas de Software

iSys - Revista Brasileira de Sistemas de Informação, Rio de Janeiro, vol. 7, No. 3, p. 19-37, 2014. 
Iyer, B. (2012) "EcoSysNetworks: A Method for Visualizing Software Ecosystems", In: Proceedings of the 4th International Workshop on Software Ecosystems, 3rd International Conference on Software Business, Boston, USA, pp. 1-5.

Jansen, S., Brinkkemper, S., Finkelstein, A. (2009) "Business Network Management as a Survival Strategy: A Tale of Two Software Ecosystems", In: Proceedings of the First International Workshop on Software Ecosystems, 11th International Conference on Software Reuse, Falls Church, USA, pp. 34-48.

Lima, T., Santos, R., Werner, C. (2013) "Apoio à Compreensão das Redes Sociotécnicas em Ecossistemas de Software". In: Anais do XXXIII Congresso da Sociedade Brasileira de Computação, II Brazilian Workshop on Social Network Analysis and Mining, Maceió, Brasil, pp. 1525-1530.

Manikas, K., Hansen, K.M. (2013) "Software ecosystems - A systematic literature review". Journal of Systems and Software, v. 86, n. 5 (May), pp. 1294-1306.

Mens, T., Goeminne, M. (2011) "Analysing the Evolution of Social Aspects of Open Source Software Ecosystems". In: Proceedings of the 3rd International Workshop on Software Ecosystems, 2rd International Conference on Software Business, Brussels, Belgium, pp. 77-88.

Rios, L. (2013) "Governança de Ativos em Ecossistemas de Software na Biblioteca Brechó". Projeto Final de Curso. Escola Politécnica/UFRJ, Rio de Janeiro, Brasil.

Russ, C. (2007) "Online Crowds - Extraordinary Mass Behavior on the Internet". In: Proceedings of the I-MEDIA, Graz, Austria, pp. 65-76.

Santos, R.P. (2013) "Engenharia e Gerenciamento de Ecossistemas de Software". Exame de Qualificação de Doutorado. COPPE/UFRJ, Rio de Janeiro, Brasil.

Santos, R.P., Oliveira, J. (2013) "Análise e Aplicações de Redes Sociais em Ecossistemas de Software" In: Anais do IX Simpósio Brasileiro de Sistemas de Informação, Minicursos, João Pessoa, Brasil, v. 2, pp. 19 - 24

Santos, R.P., Werner, C., (2012) "ReuseECOS: An Approach to Support Global Software Development through Software Ecosystems", In: Proceedings of the 7th IEEE International Conference on Global Software Engineering Workshops, VI Workshop on Distributed Software Development, Porto Alegre, Brazil, pp. 60-65.

Santos, R.P., Werner, C. (2013) "On the Impact of Software Ecosystems in Requirements Communication and Management". In: Proceedings of the ER@BR, IEEE International Conference on Requirements Engineering, Rio de Janeiro, Brazil pp. 190-195.

Santos, R.P., Werner, C., Silva, M. (2010) "Brechó-VCM: A Value-Based Approach for Component Markets". International Transactions on Systems Science and Applications, v. 6, n. 2/3 (August), pp. 179-199.

Santos, R.P., Esteves, M., Freitas, G., Souza, J. (2012) 'Utilizando Redes Sociais Para Apoiar os Ecossistemas de Software", In: Anais do XXXII Congresso da Sociedade Brasileira de Computação, I Brazilian Workshop on Social Network Analysis and Mining, Curitiba, Brasil, pp. 1-4.

Santos, R.P., Tostes, L., Werner, C. (2013) “A Brechó-EcoSys Extension to Support Negotiation in the Software Ecosystems Context". In: Proceedings of the 14th IEEE 
International Conference on Information Reuse and Integration, San Francisco, USA, pp. 578-585.

Santos, R.P., Esteves, M., Freitas, G., Souza, J. (2014) "Using Social Networks to Support Software Ecosystems Comprehension and Evolution", Social Networking, v. 2, n. 2 (February), pp. 108-118.

Seichter, D., Dhungana, D., Pleuss, A., Hauptmann, B. (2010) "Knowledge Management in Software Ecosystems: Software Artefacts as First-class Citizens", In: Proceedings of the 4th European Conference on Software Architecture, 2nd International Workshop on Software Ecosystems, Copenhagen, Denmark, pp. 119126.

SPB (2014) "Portal do Software Público Brasileiro". Disponível em: http://softwarepublico.gov.br/. Acessado em 22 abr 2014.

Szyperski, C., Gruntz, D., Murer, S. (2002) "Component Software - Beyond ObjectOriented Programming”. 2. ed. New York, NY, USA, Addison-Wesley and ACM Press.

Werner, C., Murta, L., Marinho, A., Santos, R., Silva, M. (2009) "Towards a Component and Service Marketplace with Brechó Library". In: Proceedings of the IADIS International Conference WWW/Internet 2009, Rome, Italy, pp. 567-574.

Williams, C., O'Connor, S. (2011) "Four best Practices for Software Asset Management". BCM Software Industry Insights. 